\title{
SPINOCEREBELLAR ATAXIAS
}

\author{
Hélio A.G. Teive
}

\begin{abstract}
Spinocerebellar ataxias (SCAs) constitute a heterogeneous group of neurodegenerative diseases characterized by progressive cerebellar ataxia in association with some or all of the following conditions: ophthalmoplegia, pyramidal signs, movement disorders, pigmentary retinopathy, peripheral neuropathy, cognitive dysfunction and dementia. Objective: To carry out a clinical and genetic review of the main types of SCA. Method: The review was based on a search of the PUBMED and OMIM databases. Results: Thirty types of SCAs are currently known, and 16 genes associated with the disease have been identified. The most common types are SCA type 3, or Machado-Joseph disease, SCA type 10 and SCA types 7, 2, 1 and 6. SCAs are genotypically and phenotypically very heterogeneous. A clinical algorithm can be used to distinguish between the different types of SCAs. Conclusions: Detailed clinical neurological examination of SCA patients can be of great help when assessing them, and the information thus gained can be used in an algorithm to screen patients before molecular tests to investigate the correct etiology of the disease are requested.
\end{abstract}

KEY WORDS: spinocerebellar ataxias, cerebellar atrophy, genotype, phenotype.

\begin{abstract}
Ataxias espinocerebelares
Resumo - As ataxias espinocerebelares (AECs) compreendem um grupo heterogeneo de enfermidades neurodegenerativas, que se caracterizam pela presença de ataxia cerebelar progressiva, associada de forma variada com oftalmoplegia, sinais piramidais, distúrbios do movimento, retinopatia pigmentar, neuropatia periférica, disfunção cognitiva e demência. Objetivo: Realizar uma revisão clínico-genética dos principais tipos de AECs. Método: A revisão foi realizada através da pesquisa pelo sistema do PUBMED e do OMIM. Resultados: $\mathrm{Na}$ atualidade existem cerca de 30 tipos de AECs, com a descoberta de 16 genes. Os tipos mais comuns são a AEC tipo 3, ou doença de Machado-Joseph, a AEC tipo 10, e as AECs tipo 7, 2 1, e 6. As AECs apresentam grande heterogeneidade genotípica e fenotípica. Pode-se utilizar um algoritmo clínico para a pesquisa dos diferentes tipos de AECs. Conclusões: O exame clínico neurológico minucioso nos pacientes com AECs pode auxiliar sobremaneira na avaliação clínica destes pacientes, utilizando-se desta forma de um algoritmo, com os dados clínicos, que pode servir como um instrumento de triagem para a solicitação dos testes de genética molecular, para a correta investigação etiológica.
\end{abstract}

PALAVRAS-CHAVE: ataxias espinocerebelares, atrofia cerebelar, genótipo, fenótipo.

Spinocerebellar ataxias (SCAs) constitute a large, complex group of heterogeneous autosomal dominant degenerative diseases characterized by progressive degeneration of the cerebellum and its afferent and efferent connections. Other nervous system structures are usually affected, including the basal ganglia, brainstem nuclei, pyramidal tracts and posterior column and anterior horn of the spinal cord, as well as the peripheral nerves ${ }^{1-8}$.

SCAs are clinically characterized by the presence of cerebellar gait and limb ataxia (with dysmetria, dysdiado- chokinesia, intention tremor, dysarthria and nystagmus), which may be accompanied by extracerebellar signs such as ophthalmoplegia, pyramidal signs, movement disorders (including parkinsonism, dystonia, myoclonia and chorea), dementia, epilepsy, visual disorders (including pigmentary retinopathy), lower motor neuron disease and peripheral neuropathy ${ }^{1-10}$.

Harding classified SCAs, which had until then been defined as autosomal dominant cerebellar ataxias (ADCAs), into four basic types defined as follows:

MD, PhD, Movement Disorders Unit, Neurology Service, Internal Medicine Department, Hospital de Clínicas, Federal University of Paraná, Curitiba PR, Brazil.

Received 9 August 2009. Accepted 11 August 2009.

Dr. Helio A.G. Teive - Rua General Carneiro 1103/102 - 80060-150 Curitiba PR - Brasil. E-mail: hagteive@mps.com.br 
Type 1 is characterized by cerebellar ataxia with optic atrophy, ophthalmoplegia, dementia, amyotrophy and extrapyramidal signs.

Type 2 involves retinal degeneration and can be accompanied by ophthalmoplegia and extrapyramidal signs.

Type 3 can be considered a type of "pure" cerebellar ataxia, while type 4 may present with deafness and myoclonia in addition to the cerebellar ataxia".

SCAs have an prevalence of around 1 to 5 cases per 100,000 people pli, $^{12,3}$.

SCA type 3 is the most common form of the disease worldwide; types 1, 2, 6, 7 and 8 have greatly varying prevalences depending on the ethnic background of the population ${ }^{1,2,14-19}$.

As a general rule, certain types of spinocerebellar ataxia have a higher incidence in particular countries. Table 1 shows the geographic variation in the prevalence of the main spinocerebellar ataxias in various countries.

In Brazil, Cassa carried out an epidemiologic study in 1996 in which he investigated the prevalence of hereditary ataxias - Machado-Joseph disease (MJD) in particular - in the states of Minas Gerais, São Paulo, Goiás and Espírito Santo. He found that 426 patients in 33 families had SCA, corresponding to a mean incidence of 6.55 cases per $100,000$ people (with variations from 0.78 to 228$)^{20}$.

In 1997 Lopes-Cendes et al. investigated the frequency of mutations that cause SCAs (SCA1, SCA2, SCA3 and dentatorubral-pallidoluysian atrophy - DRPLA) in a large series of Brazilian patients. They found that a mutation was present in $59 \%$ of their cases and that SCA 3 was present in $44 \%$ of these, SCA 2 in $9 \%$ and SCA 1 in $6 \%^{15}$.

In 2001 Jardim et al. carried out a study of SCAs in the state of Rio Grande do Sul in which they investigated 66 cases of the disease. The authors concluded that the incidence of MJD found was very high and suggested that this might have been due to the presence of a founder effect of Azorean origin. They estimated the incidence of MJD in the region to be $1.8 / 100,000$ and that of other forms of autosomal dominant ataxia to be $0.2 / 100,000^{17}$.

In a southern Brazilian series of 100 families with SCAs, a mutation was identified in two-thirds of the cases. SCA 3 was the most frequent form of the disease $(73.5 \%)$, followed by SCA 10 (11.8\%), SCA 2 (7.4\%), SCA 7 (4.4\%), SCA 1 $(2.9 \%)$ and SCA $6(1.5 \%)^{16}$.

The whole degenerative neuropathological process has been studied in depth in transgenic mice and Drosophila models of SCAs $s^{1,36-8}$.

Neuroimaging, particularly magnetic resonance imaging, reveals cerebellar atrophy, with or without brainstem involvement (olivopontocerebellar atrophy) ${ }^{1-8}$.

The onset of SCAs usually occurs between 30 and 50 years of age; however, cases starting before the age of 20 and after the age of 60 have been described ${ }^{1-3}$.
Table 1. Spinocerebellar ataxias (SCA): geographic variation of prevalence.

\begin{tabular}{ll}
\hline SCA & Prevalence \\
\hline SCA 1 & Italy, United Kingdom (UK), France, \\
SCA 2 & Cuba, India, UK, France, USA \\
SCA 3 & Portugal, Brazil, Germany, Japan, China \\
SCA 6 & Japan, Australia, Germany \\
SCA 7 & Sweden, Finland, USA, China \\
SCA 10 & México, Brazil \\
DRPLA & Japan. \\
\hline
\end{tabular}

DRPLA: dentatorubral-pallidoluysian atrophy.

Current previously unimaginable advances in molecular genetic techniques together with the use of PCR (polymerase chain reaction) have resulted in various genetic loci and genes being identified on different chromosomes, allowing a more rational clinical and genetic classification of the disease $\mathrm{s}^{1-3,8,21-24}$.

Table 2 shows the main types of SCAs currently known and gives the genetic loci, mutations and proteins associated with the disease.

The phenotypical classification of SCAs described by Harding in 1984 can be compared with the current genotypical classification ${ }^{8,11}$. Table 3 gives a summary of this comparison.

\section{SCAs-GENETIC ASPECTS}

Thirty different types of SCA, known as SCA 1 to SCA 30 , have been identified to date. The particular gene responsible for each type of the disease has been identified for SCAs types 1-3, 5-8, 10-15, 17, and 27. The other types SCAs 4, 18-23, 25, 26, 28, 29 and 30 - have been defined by linkage studies, as the genes and mutations associated with them have not yet been identified ${ }^{1,2,19,2,22}$.

It should be stressed that SCAs types 9 and 24 remain undefined and that these two type numbers have been reserved for disorders yet to be described in the literature. The mutation in the puratrophin-1(PLEKHG4) gene on chromosome 16q22 is associated with the pure Japanese form of SCA 4 (without sensory axonal neuropathy) and was redefined as SCA 4R. SCA 6 has been identified as being identical to SCA 15. SCA types 29 and 15 and 22 and 19 , may represent different allelic forms of the same gene $e^{1,2,19}$.

SCA types 1, 2, 3, 6, 7 and 17 and dentatorubral pallidoluysian atrophy (DRPLA) are caused by mutations in the coding region of the disease gene characterized by the presence of an expanded, unstable polymorphic CAG trinucleotide repeat. The product of the gene is a protein known as ataxin. This protein contains polyglutamine stretches, and these disorders are now known as polyglutamine diseases $^{8}$. The mutant protein ataxin can cause neurodegen- 
Table 2. Spinocerebellar ataxias (SCA): summary of genetics defects.

\begin{tabular}{|c|c|c|c|c|}
\hline SCA & Chromossome & Gene & Mutation & Protein \\
\hline SCA 1 & $6 p 22.3$ & ATAXIN1 & CAG & Ataxin 1 \\
\hline SCA 2 & $12 q 24.13$ & ATAXIN2 & CAG & Ataxin 2 \\
\hline SCA 3 & $14 q 32.12$ & ATAXIN3 & CAG & Ataxin 3 \\
\hline SCA 4 & 16q24-qter & SCA4 & (PLEKHG4) ? & - \\
\hline SCA 5 & 11q13.2 & SPTBN2 & $\mathrm{D} / \mathrm{MM}$ & Beta-III Spectrin \\
\hline SCA 6 & 19p13.13 & CACNA1A & CAG & CACNA1A \\
\hline SCA 7 & 3p14.1 & ATXN7 & CAG & Ataxin.7 \\
\hline SCA 8 & $13 q 21$ & KLHLIAS & CTG & Kelch-like 1 \\
\hline SCA 9 & $?$ & - & - & - \\
\hline SCA 10 & $22 q 13.31$ & ATXN10 & АТTCT & Ataxin.10 \\
\hline SCA 11 & $15 q 14-q 21.3$ & SCA11 & - & - \\
\hline SCA 12 & $5 q 32$ & PPP2R2B & CAG & PPP2R2B \\
\hline SCA 13 & $19 q 13.33$ & KCNC3- & MM & KCNC3 \\
\hline SCA 14 & $19 q 13.42$ & PRKCG & MM & PRKCG \\
\hline SCA 15 & $3 p 24.2-3 p t r$ & ITPR1 & PM & - \\
\hline SCA 16 & $8 q 23-q 24.1$ & - & - & - \\
\hline SCA 17 & $6 q 27$ & TBP & CAG & TBP \\
\hline SCA 18 & $7 q 31-q 32$ & - & - & - \\
\hline SCA 19 & 1p21-q21 & - & - & - \\
\hline SCA 20 & 11 & - & - & - \\
\hline SCA 21 & 7p21.3-p15.1 & - & - & - \\
\hline SCA 22 & $1 p 21-q 23$ & - & - & - \\
\hline SCA 23 & 20p13-p12.2 & - & - & - \\
\hline SCA 24 & 1p36 & - & - & - \\
\hline SCA 25 & 2p21-p15 & - & - & - \\
\hline SCA 26 & 19p13.3 & - & - & - \\
\hline SCA 27 & $13 q 33.1$ & FGF14 & MM & FGF14 \\
\hline SCA 28 & 18p11.22-q11.2 & - & - & - \\
\hline SCA 29 & $3 p 26$ & - & - & - \\
\hline SCA 30 & $4 q 34.3-q 35.1$ & - & - & - \\
\hline DRPLA & 12p13.31 & ATN1 & CAG & Atrophin 1 \\
\hline EA 1 & $12 q 13$ & KCNA1 & PM & K Channel \\
\hline EA 2 & 19p13 & CACNA-1A & PM & Ca Channel \\
\hline EA 3 & lq42 & & & \\
\hline \multicolumn{5}{|l|}{ EA 4} \\
\hline EA 5 & $2 q 22-q 23$ & CACNB4 & PM & Cav2.1 \\
\hline EA 6 & $5 p$ & SLCIA3 & PM & EAATI \\
\hline Others EA & & & & \\
\hline
\end{tabular}

D: deletion; MM; "missense" mutation; PM; point mutation; EA: episodic ataxia.

eration by a gain of toxic function that triggers the degenerative process, forming nuclear inclusions in cerebellar Purkinje cells, with clear involvement of the ubiquitin proteasome pathway as well as the system of proteins known as chaperones. In short, neurodegenerative polyglutamine diseases are characterized by expansion of a polyglutamine stretch within the mutant protein that causes the illness. Expression of the mutant protein induces progressive loss of neuronal function and subsequent neurodegeneration of a specific group of neurons for each disease ,, $21-24^{\text {. }}$
A characteristic that is particular to these types of SCAs is the phenomenon of anticipation, i.e., the increasingly early onset and increasingly severe nature of the clinical picture in successive generations of affected families. The phenomenon of anticipation is related to the number of expanded CAG repeats ${ }^{1-3,5-8}$.

A second group of SCAs, which includes SCAs types 8,10 and 12 , is caused by a repeat expansion that is located outside the coding region of the genes associated with the disease and results in deregulation of gene expression 
Table 3. Spinocerebellar ataxias (SCA): comparison between Harding's classification (phenotype) and the genotype.

\begin{tabular}{lll}
\hline Harding's classification & Phenotype & Genotype \\
\hline ADCA type I & Ataxia + degeneration of other neuronal systems & SCA types 1, 2, 3, 4, 8, 12, 13, 17, 18, 19, \\
& & $20,21,23,24,25,27,28$, and DRPLA \\
ADCA type II & Ataxia + degeneration of retina & SCA type 7 \\
ADCA type III & Pure cerebellar ataxia & SCA 5, 6, 8, 10, 11, 12, 14, 15, 16, 26, 29, and 30 \\
ADCA type IV & Ataxia + myoclonus & SCA types 14, 19, 24 and DRPLA \\
\hline
\end{tabular}

ADCA: autosomal dominant cerebellar ataxia; DRPLA: dentatorubral-pallidoluysian atrophy.

Table 4. Spinocerebellar ataxias (SCA): normal and expanded nucleotide repeat sequences*.

\begin{tabular}{cccc}
\hline SCA & Nucleotide repeat & Normal & Expanded \\
\hline SCA 1 & CAG & $6-39$ & $40-82$ \\
SCA 2 & CAG & $14-31$ & $33-64$ \\
SCA 3 & CAG & $12-42$ & $54-86$ \\
SCA 6 & CAG & $4-18$ & $19-30$ \\
SCA 7 & CAG & $4-27$ & $37-200$ \\
SCA 8 & CTA/CTG & $16-91$ & $107-127$ \\
SCA 10 & ATTCT & $10-21$ & $800-4500$ \\
SCA 12 & CAG & $7-32$ & $55-78$ \\
SCA 17 & CAG & $25-44$ & $47-63$ \\
DRPLA & CAG & $6-36$ & $49-79$ \\
\hline
\end{tabular}

*Modified from Pulst and Subramony ${ }^{8,18}$.

(duenas). SCA 8 is associated with a CTG expansion; SCA 10 with a pentanucleotide (ATTCT) repeat; and SCA 12 is caused by deregulation of the activity of protein phosphatase 2 (PP2), an enzyme that has an important function in Purkinje cells ${ }^{1-3}$.

A third group of SCAs - types 5, 11, 13, 14, 15 and 27 are caused by different mechanisms involving changes in the amino acid composition of the following proteins: $\beta$ III spectrin, tau tubulin kinase (TTBK2), potassium channels (KCNC3), protein kinase C (PRKCG), inositol 1,4,5-triphosphate receptor, type 1 (ITPR1) and fibroblast growth factor 14 (FGF14), respectively ${ }^{1-3}$.

Table 4 gives a summary of the normal and expanded nucleotide repeat sequences found in the main types of spinocerebellar ataxias.

\section{SCAs - THE MOST FREQUENT TYPES IN SOUTHERN BRAZIL}

\section{SCA 3 (Machado-Joseph disease)}

This form of autosomal dominant ataxia, which is known as Machado-Joseph disease (MJD), has been described as the most common form of SCA identified in different molecular genetic studies throughout the world 1 1-3,5-8,14-20,25.

The disease is characterized by a CAG triplet expan- sion that has been mapped to chromosome $14 \mathrm{q} 32.12$ and has from 56 to 86 repeats $^{1-3,8,16,17,25}$.

Neuropathological features include neuronal loss with reactive gliosis in the following structures: the substantia nigra; the dentate nucleus of the cerebellum; the red nucleus; the pontine nuclei and the nuclei of other motor cranial nerves; Clarke's column; cells in the anterior horn of the spinal cord; and the spinocerebellar tracts. The globus pallidus can also be affected. Involvement of the olivary nuclei and the cerebellar and cerebral cortex is uncommon ${ }^{1-5,7}$.

Studies using neuroimaging show the presence of pontocerebellar atrophy, usually without involvement of the olives. However, a study by Murata et al. published in 1998 in which the authors used magnetic resonance imaging also showed the presence of pontocerebellar atrophy and atrophy of the globi pallidi and frontal and temporal lobes ${ }^{2,3,26}$.

MJD sometimes presents with cerebellar ataxia in association with pyramidal signs; peripheral amyotrophy; nystagmus, ophthalmoparesis and bulging eyes; fasciculations of the face, tongue and occasionally the limbs; and dystonia and parkinsonism ${ }^{1-5,27-29}$.

In 1980 Lima and Coutinho proposed the following diagnostic criteria for MJD: autosomal dominant inheritance, major neurological signs: cerebellar ataxia, pyramidal signs, extrapyramidal signs and amyotrophy, minor neurological signs: progressive external ophthalmoplegia, dystonia, fasciculations and bulging eyes ${ }^{28}$.

In 1992 Paula Coutinho proposed the following criteria for diagnosing MJD in her PhD thesis: autosomal dominant transmission, onset in adult life, presence of ataxia, supranuclear ophthalmoparesis and pyramidal and extrapyramidal signs, with involvement of the peripheral nervous system, minor signs: fasciculations and bulging eyes, normal higher cortical functions, mean survival of 21 years ${ }^{30}$.

\section{SCA 10}

SCA 10 was first described in families of Mexican origin. It has well-defined clinical characteristics: patients present with a "pure" cerebellar syndrome, often accompanied by epilepsy and sometimes by peripheral neuropathy ${ }^{16,31,32}$. 
The disease-causing mutation that leads to SCA 10 is a large expansion of a pentanucleotide (ATTCT) repeat located in an intron of a gene of unknown function (SCA 10) on chromosome $22 q^{16,31-34}$.

The DNA test for SCA 10 has $100 \%$ sensitivity and specificity and can be performed by PCR or Southern blot analysis. The size of the expanded alleles range from 800 to 4500 ATTCT repeats for a diagnosis of SCA $10^{33-35}$.

As a general rule, there is an inverse correlation between age at onset of SCA 10 and the size of the ATTCT repeat expansion ${ }^{33-35}$.

Neuroimaging studies, particularly magnetic resonance imaging of the brain, show the presence of pan-cerebellar atrophy without any abnormalities in other regions ${ }^{16,31,32}$.

To the author's knowledge there are no descriptions of neuropathological examinations of patients with SCA 10 , nor any studies with experimental models. Hence, the mechanism of this type of SCA is completely unknown ${ }^{16,31,32}$.

In 2001 Rasmunssen et al. published a seminal study in which they described the clinical and genetic analysis of 18 patients in four Mexican families with SCA 10. The mean age at onset among the affected patients was 26.7 years (varying from 14 to 44 years), and the number of ATTCT repeats varied from 920 to 4140 . The authors did not observe any significant anticipation or any correlation between age at onset of the disease and the number of ATTCT repeats. In addition to cerebellar ataxia and epilepsy (found in $72.2 \%$ of the cases), clinical findings included peripheral polyneuropathy in $66 \%$ of the cases (confirmed by a nerve conduction study) and cerebellar atrophy, which was predominant in MRI examinations; in some cases mild pyramidal signs, ocular dyskinesia, cognitive dysfunction and/or behavioral disorders were observed, as well as liver, heart and hematological dysfunction ${ }^{31}$.

Until the study by Rasmunssen et al., SCA 10 had only been found in patients of Mexican descent. In 2002 Matsuura et al. investigated the presence of the SCA $10 \mathrm{mu}$ tation in populations other than the Mexican population (white patients in North America, French Canadians, Italians, Spanish and Japanese) and failed to find any cases ${ }^{36}$. Fujigasaki et al. also failed to detect the mutation in patients from France ${ }^{37}$.

In 2004 Teive et al. published a study of five Brazilian families with confirmed diagnoses of SCA 10 with a different phenotype, namely, a form of pure cerebellar ataxia without epilepsy or peripheral neuropathy. Around 70\% of the families were of Amerindian ancestry ${ }^{16}$.

In 2006 Raskin et al. published a report of a genetically proven case of SCA 10 with cerebellar ataxia, cognitive dysfunction and epilepsy. Expansion of an ATTCT pentanucleotide repeat was present in various members of the family, all of whom were asymptomatic, showing that the case had incomplete penetrance ${ }^{38}$.

\section{SCA 7}

This type of SCA presents with cerebellar ataxia and progressive visual deficit caused by retinal degeneration (macular dystrophy). It can also be accompanied by pyramidal signs, ophthalmoplegia, parkinsonism and slow saccadic movements in particular ${ }^{3-6}$.

The neuropathological features are olivopontocerebellar degeneration in association with loss of retinal ganglion cells and pigmentary macular dystrophy ${ }^{3-6}$.

The locus of SCA 7 was mapped to chromosome 3 (3p14.1) by David et al. in 1996. One of the families they studied came from the Crateús region, in Ceará, Brazil ${ }^{39}$.

The pathological alleles have between 36 and 306 CAG repeats. The mutant protein, which is known as ataxin 7 and has an unknown function, is expressed in many tissues, including the central nervous system, and only causes selective neuron death in the brain ${ }^{3-6,39}$.

The clinical picture can emerge from early infancy to the end of the fifth decade and progresses much more quickly in cases involving early onset of the condition. Anticipation may be present in these families ${ }^{3-6,39}$.

Although a less-common form of SCA, this type is found in various countries and is considered the most common form in Sweden and Finland $d^{3-6,39,40}$.

\section{SCA 2}

SCA 2 is characterized by cerebellar ataxia accompanied by dysarthria, tremor, hypoactive deep reflexes/arreflexia of the upper and lower limbs (defining the presence of associated peripheral neuropathy), fasciculations of the face and limbs, and characteristic slow saccadic eye movements ${ }^{3-10}$.

The main clinical characteristic of SCA 2 is the presence of cerebellar ataxia, cerebellar atrophy, which can be observed in neuroimaging examinations, peripheral neuropathy and slow saccadic eye movements. Other clinical manifestations are dystonia, chorea, parkinsonism, myoclonia and dementia ${ }^{3-10}$.

The first description of SCA 2 was by Wadia and Swa$\mathrm{mi}$, in India in 1971, and the disease was later the subject of considerable study by Orozco in Cuba (Holguín) in $1990^{41,42}$. Salem et al., using molecular analysis, studied 42 Indian families with SCA and concluded that SCA 2 was the most common form. The authors also found evidence of a common founding mutation ${ }^{43}$. Basu et al., investigating a series of nine different ethnic populations in India, concluded that SCA 2 was the most common ${ }^{44}$. Velazquez-Perez studied 125 families with SCA in Cuba and concluded that SCA 2 (present in 120 families) was the most common form. There was a high prevalence of this form of the disease in the province of Holguin $170 \%$ of the patients), especially in the city of Baguanos (where there was an incidence of 129.2 cases per 100,000 inhab- 
itants), representing one of the highest rates of SCA in the world. SCA 2 has also been described in other countries with varying frequency ${ }^{45}$.

SCA 2 is characterized by cerebellar atrophy, with a loss of Purkinje and granular cells, olivary neurons, substantia nigra and cells in the anterior horn of the spinal cord ${ }^{3-10}$.

The SCA 2 locus has been mapped to chromosome 12 (12q24.13), and the genetic mutation responsible for the disease is a CAG trinucleotide expansion with between 34 and 59 repeats. However, late onset of SCA 2 with a 33 CAG repeat expansion, which is sufficient to cause the disease, has been reported ${ }^{3-10}$.

SCA 2 is characterized by cerebellar ataxia with dysarthria, tremor, hyporeflexia/deep areflexia of the upper and lower limbs (defining the presence of associated peripheral neuropathy), fasciculations of the face and limbs, and characteristic slow saccadic eye movements ${ }^{3-10}$.

The main clinical characteristic of SCA 2 is its association with cerebellar ataxia (with cerebellar atrophy being observed in neuroimaging examinations), peripheral neuropathy and slow saccadic eye movements. Other clinical manifestations are dystonia, chorea, parkinsonism, myoclonia and dementia ${ }^{3-10}$. Cognitive deficits have been described in patients with SCA 2 with a frequency of 5 to $19 \%{ }^{46}$.

SCA 2 is characterized by cerebellar atrophy with a loss of Purkinje and granular cells, olivary neurons, substantia nigra and cells in the anterior horn of the spinal cord $^{3-10}$

SCA 2 locus has been mapped to chromosome 12 (12q24.13), and the genetic mutation responsible for the disease is a CAG trinucleotide expansion with between 34 and 59 repeats ${ }^{3-10,43-45}$.

\section{SCA 1}

Age of onset for SCA 1 is usually after 20 years of age, and the disease manifests itself as gait imbalance, with ataxia (more pronounced in gait than in the limbs), dysarthria, nystagmus, hyperactive deep reflexes and, sometimes, ophthalmoparesia. The most common abnormal eye movement in SCA 1 is a significant increase in the amplitude of saccadic movements, leading to hypermetria. It can occasionally be associated with slow saccadic eye movements, bulbar paralysis, dystonia, chorea and cognitive dysfunction ${ }^{2-10}$.

Pathological examinations show that the systems most affected are the cerebellum (through loss of Purkinje cells and cells in the dentate nucleus), pons, middle cerebellar peduncle and olives ${ }^{4}$.

The disease was mapped to chromosome 6 (6p 22.3) - in fact, it was the first ataxia locus ever mapped - and the genetic mutation was defined as an unstable expansion of a repeated CAG sequence (generally between 41 and 81 repeats) ${ }^{2-10}$.
The number of CAG repeats is related to the age at which signs and symptoms first appear as well as the duration of the disease. In some cases a correlation was found between the pattern of transmission (for example, paternal transmission) and a greater increase in the number of CAG repeats, as well as the phenomenon of anticipation ${ }^{2-10}$.

This form of SCA corresponds to the entity previously described by Schut and Haymaker in $1951^{4}$.

SCA 1 has been detected in 4 to $19 \%$ of cases in different series of patients with SCA. However, in some series published to date, it is the most common form of SCA found; in some regions of Italy and Japan, for example, it represents $50 \%$ of all cases cen $^{2,4,7,8}$.

\section{SCA 6}

Clinically, this form of SCA is characterized by "pure" cerebellar ataxia, which can be accompanied by dysarthria, nystagmus, dysphagia and even loss of proprioception and dystonia. Many patients have intense episodes of vertigo before the onset of ataxia, while in others there are intermittent episodes of ataxia (corresponding to episodic ataxia type 2) in parallel with the signs and symptoms of slowly progressive cerebellar ataxia, ${ }^{3,447}$.

Generally, SCA 6 evolves slowly and progressively, with the clinical picture first appearing around 50 years of age ${ }^{3,4,47}$.

Neuroimaging reveals cerebellar atrophy, and pathological examination shows a loss of Purkinje cells in the cerebellar cortex as well as gliosis of the inferior olivary complex. Ishikawa et al. described the presence of polyglutamine aggregates in both the nucleus and cytoplasm of Purkinje cells in patients with SCA $6^{3,4,47}$.

This SCA is characterized genetically by an expansion of a CAG repeat between 21 and 31 units long in the gene responsible for the voltage-dependent calcium channel known as alpha $1^{A}$ (CACNA1A4), which was mapped to chromosome 19p13.133,4,47.

SCA 6 accounts for between 10 and $30 \%$ of all SCAs and is the second most common form of SCA in some series (e.g., in Japan). However, in certain regions of Japan, such as the district of Kinski, this type of SCA is the most common form ${ }^{1,3,4,47}$.

From the clinical point of view, it is particularly important to stress that the SCA 6 mutation is allelic with episodic or sporadic SCA type 2 and hemiplegic migraine $^{3,4,47}$.

\section{SCAs - RARE TYPES \\ SCA 8}

This is a new form of SCA characterized by the presence of "pure" cerebellar ataxia that progresses slowly and can be accompanied by eye movement disorder, dysarthria and, less commonly, spasticity, tremor and cogni- 
tive disorder. Imaging tests reveal cerebellar atrophy, with a relatively preserved brainstem ${ }^{3-10}$.

This type of SCA is unique among the various SCAs, as it has a very complex genetic inheritance pattern. It is characterized genetically by an (extremely variable) CTG expansion that has been mapped to chromosome 13 (13q21). Some patients with CTG allelic expansions never develop the disease, raising doubts about the true pathogenic role of the expansion, i.e., the true relationship between the repeat expansion in the SCA 8 gene and the presence of cerebellar ataxia ${ }^{2-10}$.

SCA 8 is a rare form of SCA and has been described in a small number of cases in various countries, such as Finland, Japan, the USA, Italy, Spain and Scotland ${ }^{4}$.

\section{SCA 12}

This form of SCA was described in 1999 by Holmes et al. in a family of German origin known as R. The onset of symptoms usually occurs in the fourth decade of life, with tremor in the upper limbs, and as the disease progresses, gait ataxia, head tremor, dysmetria, hyperactive deep reflexes, abnormal eye movements and, later, dementia. MRI reveals atrophy of the cerebellum and cerebral cortex ${ }^{3-10}$.

The disease was defined to be the result of an expansion of a CAG trinucleotide repeat in the 5 ' region of the gene complex known as PPP2R2B (mapped to 5q32), which codes for a subunit of the protein phosphatase PP2A $\mathrm{A}^{3-10}$.

In 2001 Fujigasaki et al. reported an Indian family with SCA 12, and Srivastava et al. subsequently reported five more Indian families with this form of the disease ${ }^{48,49}$. However, Chofin et al. studied a number of American families with SCA and failed to find a case of SCA $12^{50}$.

\section{SCA 17}

SCA 17 is a rare form of autosomal neurodegenerative disease caused by an expansion of a CAG triplet repeat in the TBP gene (located in chromosome 6q27), which codes for the TATA binding protein, a transcription initiation factor $^{1-4,51-53}$.

The disease was described for the first time in Japan in a 14-year-old female patient whose clinical picture started at the age of 6 years and consisted of gait ataxia, followed later by intellectual deterioration. Parkinsonism and hyperactive deep reflexes can also appear as the disease progresses ${ }^{4,52}$.

SCA 17 is a rare form of autosomal dominant neurodegenerative disease caused by an expansion of a CAG triplet repeat in the TBP gene (located in chromosome 6q27) which encodes for the TATA binding protein, a transcription initiation factor ${ }^{3,4,51-53}$.

To date, a number of proven cases of SCA 17 with different clinical presentations have been described. These have a phenotype similar to that of Huntington's disease (Toyoshima et al. (5) $^{53}$, and with focal dystonia accompanied by cerebellar ataxia and dementia (Hagenah et al. $)^{54}$.

\section{SCAs - VERY RARE TYPES}

The SCA types defined as SCA 4, 5, 11, 13, 14, 15, 18, 19, $20,21,22,23,25,26,27,28,29$ and 30 represent very rare forms and have been diagnosed in a small number of cases in different parts of the world, some of which were only reported in isolated families.

The autosomal dominant form of cerebellar ataxia known as dentatorubral-pallidoluysian atrophy (DRPLA) is a disease with a highly variable phenotype; it was first described in the Japanese, among whom it was reported to have a high incidence, and has been described more recently in African Americans ("Haw River" Syndrome) and Europeans s $^{3-7,55}$.

The disease presents with cerebellar ataxia in association with three different clinical forms: (1) myoclonus epilepsy with dementia; (2) choreoathetosis with dementia (simulating Huntington's disease); and (3) a clinical picture of psychosis, parkinsonism and pyramidal signs ${ }^{4}$.

The mutation found in DRPLA is located on chromosome 12 (12p13.31) and consists of an unstable CAG expansion with 49 to 79 repeats that codes for polyglutamine $e^{4,55}$.

\section{SCAS - CLINICAL EVALUATION}

SCAs are genotypically and phenotypically very heterogeneous. The presence of phenotypic heterogeneity implies that the same genotype can determine different phenotypes, while genotypic heterogeneity implies that the same phenotype may be the result of a number of genotypes ${ }^{1-10}$.

The large number of SCAs means that their clinical diagnosis is a difficult task for the clinical neurologist.

Lopes-Cendes et al. published an interesting article about the limitations of clinical evaluation in the correct diagnosis of Machado-Joseph disease. They concluded that although most patients with SCA have common clinical characteristics, the presence of at least two different signs (such as bulging eyes, dystonia or fasciculations of the face and tongue) can help make a clinical diagnosis of MJD possible ${ }^{56}$.

Various other authors have suggested that detailed analysis of abnormal eye movements can help identify the main SCAs (types 1, 2, 3 and 6). The main abnormalities, such as changes in the amplitude and speed of saccadic movements, the presence of gaze-evoked nystagmus and impairment of the vestibulo-ocular reflex, are more common in certain types of SCA. For example, slow saccadic movements are more common in SCA 2, gazeevoked nystagmus and vestibulo-ocular reflex dysfunction are more prevalent in SCA 3 , and ocular hypermetria more common in SCA $1^{4,57}$. 
I - Autosomal dominant cerebellar ataxia + specific clinical data (A to $Q$ )

A - Episodic ataxia (EA): EA types 1,2,3,4 and 5

B - Sensory ataxia: SCA type 4

C - Visual loss: SCA type 7

D - Epilepsy: SCA type 10

E - Myoclonus + Chorea + Dementia: DRPLA

F - Oculomotor signs: go to part II - SCA types 1, 2, 3

G - Mental retardation: SCA type 13

$\mathrm{H}$ - Axial myoclonus: SCA type 14

I - Head tremor: SCA type 16

J-Dementia + Parkinsonism: SCA types 17, and 21

K - Peripheral neuropathy: SCA types 2,3,4, 10,18,24, and 25

$\mathrm{L}$ - Postural tremor + Myoclonus: SCA type 19

M - Palatal tremor + Spasmodic dysphonia: SCA type 20

$\mathrm{N}$ - Myoclonus+ Sacadic intrusions: SCA type 24

O - Postural temor + Dyskinesias: SCA type 17

P - Palpebral ptosis: SCA type 28

Q - Pure cerebellar ataxia: SCA types 5,6,8,10,11,12,14,16,22,23,26, and 30

II - Oculomotor signs (R, S, and T)

$\mathrm{R}$ - Nystagmus + Hypermetric saccades (associated to pyramidal signs): SCA type 1

$\mathrm{S}$ - Slowed saccadic eye movements + Hyporeflexia: SCA type 2

T - Nystagmus +Ophthalmoplegia + Phenotypic variation in the family (without dementia, and with other signs: Pyramidal signs+ Dystonia + Parkinsonism + Peripheral neuropathy + Amyotrophy + "Bulging eyes" + Facial fasciculations): SCA type 3 (with differents subphenotypes)

DRPLA: dentatorubral-pallidoluysian atrophy.

Schöls et al. and Garcia Ruiz et al. investigated the presence of movement abnormalities or extrapyramidal signs in patients with hereditary ataxias and concluded that the most common disturbances were parkinsonism, dystonia and postural tremor, which were particularly prevalent in SCAs types 2 and $3^{58,59}$.

In 2000 Schelhaas et al. published an interesting study of the pathogenesis of different SCAs as well as the phenotypic and genotypic similarities and differences between the diseases ${ }^{60}$. They emphasized the overlap between the phenotypes of the different forms of SCA as well as the great variation that can be observed in each SCA subtype and stated that a diagnosis should be based on genotype analysis. However, they proposed a clinical algorithm to investigate the various SCAs that takes into account different key signs and symptoms, such as retinal degeneration, eye movement disturbances and the presence of pyramidal signs ${ }^{60}$.

The information provided above gives a good insight into the difficulties frequently faced in routine neurological clinical practice when assessing patients with SCAs. Such difficulties are a result of the great genotypic heterogeneity ( 30 known loci and 16 genes already identified) and enormous phenotypic heterogeneity of the disease (as evidenced in MJD, for example).

Hence, it becomes imperative to analyze the frequen- cy of the different forms of SCAs in Brazil as well as the phenotypic and genotypic correlation between them.

It is important to take into account the different neurological signs in patients with SCAs as these could be of value when assessing patients clinically using an algorithm based on clinical data. Such clinical assessment would allow patients to be screened before molecular genetic tests are requested in order to obtain a definitive diagnosis. Table 5 shows a basic algorithm for assessing patients with SCAs.

\section{CONCLUSION}

SCAs constitute a large group of neurodegenerative diseases with a high degree of genotypic and phenotypic heterogeneity, making assessment by the clinical neurologist extremely difficult. To date, around 30 types of SCAs are known and 16 genes have been identified. Careful and meticulous clinical assessment of patients with spinocerebellar ataxias can be of significant help in choosing suitable molecular tests to ensure that the etiology is correctly defined.

\section{REFERENCES}

1. Teive HAG. Spinocerebellar degenerations in Japan: new insights from an epidemiological study. Neuroepidemiology 2009;32:184-185.

2. Duenas AM, Goold R, Giunti P. Molecular pathogenesis of spinocerebellar ataxias. Brain 2006;129:1357-1370. 
3. Schöls L, Bauer P, Schmidt T, Schulte T, Riess O. Autosomal dominant cerebellar ataxias: clinical features, genetics, and pathogenesis. Lancet Neurol 2004;3:291-304.

4. Soong BW, Paulson HL. Spinocerebellar ataxias: an update. Curr Opin Neurol 2007;20:438-446.

5. Evidente VGH, Gwinn-Hardy KA, Caviness JN, Gilman S. Hereditary ataxias. Mayo Clin Proc 2000;75:475-490.

6. Durr A, Brice A. Clinical and genetic aspects of spinocerebellar degeneration. Curr Opin Neurol 2000;13:407-413.

7. Klockgether T, Lüdtke R, Kramer B, et al. The natural history of degenerative ataxia: a retrospective study of 466 patients. Brain 1998;121: 589-600.

8. Pulst SM. Inherited ataxias: an introduction. In: Pulst SM (Ed). Genetics of movement disorders. Orlando: Academic Press 2003:19-34.

9. Everett CM, Wood NW. Trinucleotide repeats and neurodegenerative disease. Brain 2004;127:2385-2405.

10. Albin RL. Dominant ataxias and Friedreich ataxia: an update. Curr Opin Neurol 2003;16:507-514.

11. Harding AE. The hereditary ataxias and related disorders. Edimburgo: Churchill Livingstone, 1984.

12. van de Warremburg BP, Sinke RJ, Verschuuren-Bemelmans CC. Spinocerebelllar ataxias in the Netherlands: prevalence and age at onset variance analysis. Neurology 2002;58:702-708.

13. Erichsen AK, Koht J, Stray-Pedersen A, Abdelnoor M, Tallaksen ME Prevalence of hereditary ataxia and spastic paraplegia in southeast Norway: a population-based study. Brain 2009;132:1577-1588.

14. Silveira I, Lopes-Cendes I, Kish S, et al. Frequency of spinocerebellar ataxia type 1, dentatorubropallidoluysian atrophy, and Machado-Joseph disease mutations in a large group of spinocerebellar ataxia patients. Neurology 1996;46:214-218.

15. Lopes-Cendes I, Teive HAG, Calcagnotto ME, et al. Frequency of the different mutations causing spinocerebellar ataxia (SCA 1, SCA 2, SCA 3 / MJD and DRPLA) in a large group of Brazilian patients. Arq Neuropsiquiatr 1997;55:519-529.

16. Teive HAG, Roa B, Raskin S, et al. Clinical phenotype of Brazilian patients with spinocerebellar ataxia 10. Neurology 2004;63:1509-1512.

17. Jardim LB, Silveira I, Pereira ML, et al. A survey of spinocerebellar ataxia in South Brazil: 66 new cases with Machado-Joseph disease, SCA 7, SCA 8, or unidentified disease-causing mutations. J Neurol 2001; 248:870-876

18. Subramony SH, Filla A. Autosomal dominant spinocerebellar ataxias ad infinitum ? Neurology 2001;56:287-289.

19. Storey E, Bahlo M, Fahey M, Sisson O, Lueck CJ, Gardner RJM. A new dominantly inherited pure cerebellarea ataxia, SCA 30. J Neurol Neurosurg Psychiatry 2009;80:408-411.

20. Cassa E. Ataxia cerebelar autossômica dominante no Brasil: análise de 270 anos de história e genealogia, incluindo a caracterização molecular de uma grande família com doença de Machado-Joseph. Tese de Doutorado, USP-RP, Ribeirão Preto, 1996.

21. Margolis RL. The spinocerebellar ataxias: order emerges from chaos. Curr Neurol Neurosci Rep 2002;2:447-456.

22. Bandmann $\mathrm{O}$, Singleton AB. Yet another spinocerebellar ataxia: the saga continues. Neurology 2008;71:542-543.

23. Gatchel JR, Zoghbi HY. Diseases of unstable repeat expansion: mechanisms and common principles. Nat Rev Genet 2005;6:743-755.

24. Pearson CE, Edamura KN, Cleary JD. Repeat instability: mechanisms of dynamic mutations. Nat Rev Genet 2005;6:729-742.

25. Jardim LB, Pereira ML, Silveira I, Ferro A, Sequeiros J, Giugliani R. Neurologic findings in Machado-Joseph disease: relation with disease duration, sybtypes, and (CAG)n. Arch Neurol 2001;58:899-904.

26. Murata Y, Yamaguchi S, Kawakami H. Characteristic magnetic resonance imaging findings in Machado-Joseph disease. Arch Neurol 1998; 55:33-37.

27. Coutinho $\mathrm{P}$, Andrade C. Autosomal dominant system degeneration in Portuguese families of the Azorean islands: a new genetic disorder involving cerebellar, pyramidal, extrapyramidal and spinal cord motor functions. Neurology 1978;28:703-709.

28. Lima L, Coutinho P. Clinical criteria for diagnosis of Machado-Joseph disease: report of a non-azorean Portuguese family. Neurology 1980;30: 319-322.

29. Sequeiros J, Coutinho P. Epidemiology and clinical aspects of Machado-Joseph disease. Adv Neurol 1993;61:139-153.

30. Coutinho P. Doença de Machado-Joseph: tentativa de definição. Tese de Doutorado, Instituto de Ciências Biomédicas, Universidade do Porto, Porto, Portugal, 1992.

31. Rasmunssen A, Matsuura T, Ruano L, et al. Clinical and genetic analysis of four Mexican families with spinocerebellar ataxia type 10. Ann Neurol 2001;50:234-239.

32. Zu L, Figueroa KP, Grewal R, Pulst S-M. Mapping of a new autosomal dominant spinocerebellar ataxia to chromosome 22. Am J Hum Genet 1999;64:594-599.

33. Matsuura T, Achari M, Khakavi M, Bachinski LL, Huda ZY, Ashizawa T. Mapping of the gene for a novel spinocerebellar ataxia with pure cerebellar signs and epilepsy. Ann Neurol 1999;45:407-411.

34. Matsuura T, Yamagata T, Burgess DL, et al. Large expansions of the ATTCT pentanucleotide repeat in spinocerebellar ataxia type 10 . Nat Genet 2000;26:191-194.

35. Matsuura T, Ashizawa T. Polymerase chain reaction amplification of expanded ATTCT repeat in spinocerebellar ataxia type 10. Ann Neurol 2002;51:271-272

36. Matsuura T, Ranum LPW, Volpini V, et al. Spinocerebellar ataxia type 10 is rare in populations other than Mexicans. Neurology 2002;58:983-984.

37. Fujigasaki H, Tardieu S, Camuzat A, et al. Spinocerebellar ataxia type 10 in the French population. Ann Neurol 2002;51:408-409.

38. Raskin S, Ashizawa T, Teive HAG, et al. Reduced penentrance associated with early-onset in a Brazilian family with spinocerebellar ataxia type 10: implications for pathogenesis, molecular genetic diagnosis and genetic couseling. Arch Neurol 2007;64:591-594.

39. David G, Giunti P, Abbas N, et al. The gene forautosomal dominant cerebellara ataxia type II is located in a 5-cM region in 3p12-p13: genetic and physical mapping of the SCA7 locus. Ann J Hum Genet 1996; 59:1328-1336.

40. Cunha Linhares S, Horta WG, Marques Jr. W. Spinocerebellar ataxia type 7 (SCA7): family princeps history, genealogy and geographical distribution. Arq Neuropsiquiatr 2006;64:222-227.

41. Wadia NH, Swami RK. A new form of heredo-familial spinocerebellar degeneration with slow eye movements (nine families). Brain 1971; 94:359-374.

42. Orozco G, Nodarse Fleites A, Cordovés Sagaz R, Auburger G. Autosomal dominant cerebellar ataxia: clinical analysis of 263 patients from a homogeneous population in Holguin, Cuba. Neurology 1990;40:1369-1375.

43. Saleem Q, Choudhry S, Mukerji M, et al. Molecular analysis of autosomal dominant hereditary ataxias in the Indian population: high frequency of SCA 2 and evidence for a common founder mutation. Hum Genet 2000;106:179-187.

44. Basu P, Chattopadhyay B, Gangopadhaya PK, et al. Analysis of CAG repeats in SCA 1, SCA 2, SCA 3, SCA 6, SCA 7, and DRPLA loci in spinocerebellar ataxia patients and distribution of CAG repeats at the SCA 1 , SCA 2 and SCA 6 loci in nine ethnic populations of eastern India. Hum Genet 2000;106:597-604.

45. Velázquez-Pérez, L, Garcia R, Santos FN, Paneque HM, Medina HE, Hechavarria PR. Hereditary ataxias in Cuba. Historical, epidemiological, clinical, electrophysiological and quantitative neurological features. Rev Neurol 2001;32:71-76

46. Bürk K, Blobas C, Bösch S, et al. Cognitive deficits in spinocerebellar ataxia 2. Brain 1999;122:769-777.

47. Teive HAG, Munhoz RP, Raskin S, Werneck LC. Spinocerebellar ataxia type 6 in Brazil. Arq Neuropsiquiatr 2008;66:691-694.

48. Fujigasaki H, Verma IC, Camuzat A, et al. SCA 12 is a rare locus for autosomal dominant cerebellara ataxia: a study of an Indian family. Ann Neurol 2001;49:117-121.

49. Srivastava AK, Choudhry S, Gopinath MS, et al. Molecular and clinical correlation in five Indian families with spinocerebellar ataxia 12. Ann Neurol 2001;50:796-800.

50. Chofin JA, Sobrido MJ, Perlman S, Pulst SM, Geschwind DH. The SCA12 mutationas as a rare cause of spinocerebellar ataxia. Arch Neurol 2001:58:1833-1835. 
51. De Michele G, Malteca F, Carella M, et al. Dementia, ataxia, extrapyramidal features, and epilepsy: phenotypespectrum in two Italian families with spinocerebellar ataxia type 17. Neurol Sci 2003;24:166-167.

52. Rolfs A, Koeppen AH, Bauer I, et al.Clinical features and neuropathology of autosomal dominant spinocerebellar ataxia (SCA17). Ann Neurol 2003;54:367-375.

53. Toyoshima Y, Yamada M, Onodera O, et al. SCA 17 homozygote showing Huntington's disease-like phenotype. Ann Neurol 2004;55:281-286.

54. Hagenah JM, Zuhlke C, Hellenbroich Y,et al. Focal dystonia as a presenting sign of spinocerebellar type 17. Mov Disord 2004;19:217-220.

55. Koide R, Ikeuchi T, Onodera O, et al.Unstable expansion of CAG repeat in hereditary dentarubralpallidoluysian atrophy (DRPLA).Nat Genet 1994;6:9-13.
56. Lopes-Cendes I, Silveira I, Maciel P, et al. Limits of clinical assessment in the acurate diagnosis of Machado-Joseph disease. Arch Neurol 1996;53:1168-1174.

57. Perlman SL. Diagnostic evaluation of ataxic patients. In: Pulst SM (Ed). Genetics of movement disorders. Edimburgo: Academic Press, 2003: 254-272.

58. Schols L, Peters S, Szymanski S, et al. Extrapiramidal motor signs in degenerative ataxias. Arch Neurol 2000;57:1495-1500

59. Garcia Ruiz PJ, Mayo D, Hernandez J et al. Movement disorders in hereditary ataxias. J Neurol Sci 2002;202:59-64.

60. Schelhaas HJ, Ippel PF, Beemer FA, Hageman G. Similarities and differences in the phenotype, genotype and pathogenesis of different spinocerebellar ataxias. Eur J Neurol 2000;7:309-314. 